SCHWEIzER, D. 1973. Differential staining of plant chromosomes with Giemsa. Chromosoma (Berl.), 40, 307-320.

SYBENGA, J., AND WOLTERS, A. H. G. 1972. The classification of the chromosomes of rye (Secale cereale L.): A translocation tester set. Genetica, 43, 453-464.

VOSA, C. G., AND MARCHI, P. 1972. Quinacrine fluorescence and Giemsa staining in plants. Nature New Biology, 237, 191-192.

\title{
MULTI-LOCUS POLYMORPHISM AND SELECTION IN A POPULATION OF DROSOPHILA MELANOGASTER
}

\section{LINKAGE DISEQUILIBRIUM ON CHROMOSOME III}

\author{
A. J. BIRLEY \\ Department of Genetics, University of Birmingham, P.O. Box 363, \\ Birmingham B15 2TT, England
}

Received 29.ix.73

\section{Summary}

Linkage disequilibrium was detected between three polymorphic loci (octanol dehydrogenase, esterase- 6 and pink) on 3rd chromosomes extracted from a population of Drosophila melanogaster. Over the chromosome segment of 12.4 centimorgans, the alleles at all three loci were not associated at random. Evidence is presented suggesting that the observed linkage disequilibria are maintained by selection.

\section{INTRODUGTION}

AT least 30 per cent of the electrophoretically detected proteins within populations of many species are polymorphic (Harris, 1966, 1969; Hubby and Lewontin, 1966; Lewontin and Hubby, 1966; Selander and Yang, 1969; Ayala and Powell, 1972). As yet the organisation of this wealth of genetic variation within the genome has received little attention from experimental population geneticists. Studies in theoretical population genetics show that a great deal of linkage disequilibrium may be the norm within populations; selection generally acts upon groups of highly correlated genes rather than upon individual loci (Franklin and Lewontin, 1970). For populations of outbreeding organisms only small amounts of linkage disequilibrium have been reported between the alleles at individual loci. In populations of Drosophila melanogaster, Mukai et al. (1971) did not find any linkage disequilibrium between three protein loci on chromosome II, and Charlesworth and Charlesworth (1971) report that only four out of 30 tests for non-random association between alleles at loci on chromosome III were statistically significant. In contrast, there is striking evidence for selectively maintained linkage disequilibria in populations of the inbreeding cereals, Hordeum vulgare (Glegg, Allard and Kahler, 1972) and Avena barbata (Allard, Babbel, Clegg and Kahler, 1972).

In the present study, linkage disequilibrium was studied between three polymorphic loci on chromosome III in a long established population of D. melanogaster. 


\section{Materials and methods}

The population of $D$. melanogaster, "Texas", used in this study was maintained in a population cage, and details of the origin and maintenance of this population are given by Barnes and Kearsey (1970). The three polymorphic loci whch were studied are Esterase-6 (Est-6), Octanol dehydrogenase $(O d h)$ and the eye mutant, pink $(p)$. The spindle-fibre of chromosome III is located at 46.0 and the map positions of the three loci are Est-6-36.8, pink-48.0 and $O d h-49 \cdot 2$ (Lindsley and Grell, 1967). The population had been polymorphic at the pink locus for at least 5 years and details of the stability of this polymorphism have been kindly made available by Drs Kearsey and Barnes of this department. The electrophoretically distinguishable allele products of the $E s t-6$ and $O d h$ loci are designated 1 for the slowest and 2 for the fastest migrating bands on a zymogram (i.e. Est-6 $6^{1}$, $\left.O d h^{1}, E s t-6^{2}, O d h^{2}\right)$.

Samples of flies were raised at high density by removing food vials from the population cage after egg-laying had stopped ( 3 days). The adults which emerged from these food vials were collected. Flies were raised at low density from eggs collected from the cage population and allowed to hatch in petri dishes containing 3 per cent agar and several drops of live yeast. Twenty larvae were transferred to a standard food vial and allowed to develop into adults.

Individual male flies were crossed to a "tester" line homozygous for pink, Est-6 and $O d h^{1}$, which had been extracted from the "Texas" population. From every male family a single female fly was taken at random and scored for its genotype at the $E s t-6$, pink and $O d h$ loci. The genetic constitution of the gamete therefore provided by the male parents could be deduced for both high and low density samples.

Starch-gel electrophoresis was used to identify the Est-6 and Odh genotypes. An 11 per cent starch (Connaught Medical Research Laboratories) gel was used. The gel and electrode buffers were the same as those described by Poulik (1957), and the staining procedures for esterase and octanol dehydrogenase were the same as those described by Ayala et al. (1972).

\section{Results}

The frequencies of the eight types of gamete, from flies raised at high and low densities, are given in table 1 . The data were analysed by using a multiway contingency $\chi^{2}$ test (Kendall and Stuart, 1961). In this analysis the four dimensions of the $2 \times 2 \times 2 \times 2$ contingency table are $E s t-6$, pink, $O d h$, and density. The analysis (table 2) tests for non-random association between alleles at both the di- and trigenic levels, and for the interaction of these di- and trigenic associations with density.

It is seen that the allele frequencies of all three loci are insensitive to density. All of the digenic interactions (Odh $\times p i n k, O d h \times E s t-6$, and Est- $6 \times$ pink), are significant. There is also a highly significant $\chi^{2}$ for the trigenic interaction, Est- $6 \times p d h \times p i n k$.

Of all these intergenic associations, only the disequilibrium between alleles at the $O d h$ and pink loci is affected by density. 
The strengths of the linkage disequilibria have been estimated by calculating the correlation coefficient $(r)$ between alleles at any two loci (table 3 ). The correlation was calculated as

$$
r=\frac{\left(g_{1} g_{4}-g_{2} g_{3}\right)}{\left(\begin{array}{llll}
p & q & r & s
\end{array}\right)_{2}^{\frac{1}{2}}} \quad(\text { Franklin and Lewontin, 1970) }
$$

where $p, q, r$ and $s$ are the frequencies of alleles $A, a$ and $B, b$ respectively, and $g_{1}, g_{2}, g_{3}, g_{4}$ are the frequencies of the four types of gamete $A B, A b, a B$, and $a b$

TABLE 1

The observed types of gamete in high and low density samples

\begin{tabular}{|c|c|c|c|c|}
\hline \multirow[b]{3}{*}{ Gametes } & \multicolumn{4}{|c|}{ Density } \\
\hline & \multicolumn{2}{|c|}{ High } & \multicolumn{2}{|c|}{ Low } \\
\hline & $\begin{array}{c}\text { Observed } \\
\text { No. }\end{array}$ & Proportion & $\begin{array}{c}\text { Observed } \\
\text { No. }\end{array}$ & Proportion \\
\hline Est- $6^{1} p O d h^{1}$ & 28 & $0 \cdot 0557$ & 20 & 0.0424 \\
\hline$E s t-6^{1}+O d h^{1}$ & 12 & $0 \cdot 0239$ & 15 & $0 \cdot 0318$ \\
\hline$E s t-6^{1} p O d h^{2}$ & 25 & 0.0497 & 34 & 0.0720 \\
\hline$E s t-6^{1}+O d h^{2}$ & 290 & 0.5765 & 267 & 0.5657 \\
\hline Est- $6^{2} p O d h^{1}$ & 24 & $0 \cdot 0477$ & 17 & $0 \cdot 0360$ \\
\hline$E s t-6^{2}+O d h^{1}$ & 3 & $0 \cdot 0060$ & 4 & 0.0085 \\
\hline Est- $6^{2} p O d h^{2}$ & 19 & $0 \cdot 0378$ & 15 & $0 \cdot 0318$ \\
\hline$E s t-6^{2}+O d h^{2}$ & 102 & $0 \cdot 2028$ & 100 & $0 \cdot 2119$ \\
\hline Total chromosomes & 503 & & 472 & \\
\hline
\end{tabular}

TABLE 2

$2 \times 2 \times 2 \times 2$ contingency $\chi^{2}$ analysis for gametic association

$$
\begin{array}{llll}
\text { Item } & \text { d.f. } & \chi^{2} & P
\end{array}
$$

(i) Allele frequency $\times$ Density

$\begin{array}{llll}\text { Est }-6 \times \text { Density } & 1 & 0 \cdot 04 & 80 \% \\ \text { pink } \times \text { Density } & 1 & 0 \cdot 12 & 70 \% \\ \text { Odh } \times \text { Density } & 1 & 0.47 & 50 \%\end{array}$

(ii) Digenic association

$\begin{array}{lrrc}\text { Odh } \times \text { pink } & 1 & 267.26 & 0.001 \% \\ \text { Est }-6 \times \text { pink } & 1 & 15.82 & 0.01 \% \\ \text { Est }-6 \times \text { Odh } & 1 & 6.68 & 1 \%\end{array}$

(iii) Digenic association $\times$ Density

$\begin{array}{lllr}\text { Odh } \times \text { pink } \times \text { Density } & 1 & 6.53 & 1 \% \\ \text { Est }-6 \times \text { pink } \times \text { Density } & 1 & 1.53 & 20 \% \\ \text { Est }-6 \times \text { Odh } \times \text { Density } & 1 & 0.19 & 65 \%\end{array}$

(iv) Trigenic association Est-6 $\times$ Odh $\times$ pink

$1 \quad 29 \cdot 86 \quad 0 \cdot 001 \%$

(v) Trigenic association $\times$ Density Est $6 \times$ Odh $\times$ pink $\times$ Density $\quad 1 \quad 0.21 \quad 65 \%$

respectively. It is noted that the significance test for linkage disequilibrium was given by the $\chi^{2}$ tests shown in table 2 .

Some insight into the nature of these disequilibria may be gleaned from the gametic proportions shown in table 3. 
In the digenic associations, the following two types of gamete were in excess of their expected (assuming random association of alleles) frequencies.

\begin{tabular}{ll} 
Locus pairs & \multicolumn{1}{c}{ Gametes in excess } \\
Odh-pink & Odh $h^{1} p, O d h^{2}+$ \\
Est-6-pink & Est- $6^{1}+, E s t-6^{2} p$ \\
Odh-Est-6 & Est- $6^{1} O d h^{2}, E s t-6^{2} O d h^{1}$
\end{tabular}

The interaction $O d h \times$ pink $\times$ density is due to a fall in the excess of $O d h^{1} p$ and $O d h^{2}+$ gametes at low compared with high density. The form of the

TABLE 3

Gametic frequencies. The expected gametic frequencies assuming random combination of alleles between the two pairs of loci are shown in brackets

\begin{tabular}{|c|c|c|c|c|c|}
\hline \multirow[b]{2}{*}{ Odh $\times$ pink } & \multicolumn{4}{|c|}{ Types of gamete } & \multirow[b]{2}{*}{$r$} \\
\hline & $O d h^{1} p$ & $O d h^{1}+$ & $O d h^{2} p$ & $O d h^{2}+$ & \\
\hline High density & $\begin{array}{c}0 \cdot 10338 \\
(0 \cdot 02542)\end{array}$ & $\begin{array}{c}0.02982 \\
(0 \cdot 10778)\end{array}$ & $\begin{array}{c}0 \cdot 08747 \\
(0 \cdot 16543)\end{array}$ & $\begin{array}{c}0.77932 \\
(0.70137)\end{array}$ & -0.58 \\
\hline Low density & $\begin{array}{c}0.07838 \\
(0.02162)\end{array}$ & $\begin{array}{c}0.04025 \\
(0.09702)\end{array}$ & $\begin{array}{c}0 \cdot 10381 \\
(0 \cdot 16058)\end{array}$ & $\begin{array}{c}0.77754 \\
(0.72078)\end{array}$ & -0.46 \\
\hline $\begin{array}{l}\text { Est }-6 \times \text { pink } \\
\text { High density }\end{array}$ & $\begin{array}{c}E s t-6^{1} p \\
0 \cdot 10538 \\
(0 \cdot 13470)\end{array}$ & $\begin{array}{c}E_{s t}-6^{1}+ \\
0.60040 \\
(0.57107)\end{array}$ & $\begin{array}{c}E s t-6^{2} p \\
0.08548 \\
(0.05615)\end{array}$ & $\begin{array}{c}E_{s t-6^{2}+} \\
0 \cdot 20874 \\
(0 \cdot 23808)\end{array}$ & $+0 \cdot 16$ \\
\hline Low density & $\begin{array}{c}0 \cdot 11440 \\
(0 \cdot 12970)\end{array}$ & $\begin{array}{c}0.59745 \\
(0.58216)\end{array}$ & $\begin{array}{c}0.06779 \\
(0.05250)\end{array}$ & $\begin{array}{c}0.22033 \\
(0.23564)\end{array}$ & +0.09 \\
\hline $\begin{array}{l}\text { Est- } 6 \times \text { Odh } \\
\quad \text { High density }\end{array}$ & $\begin{array}{c}E s t-6^{1} O d h^{1} \\
0 \cdot 07952 \\
(0.09401)\end{array}$ & $\begin{array}{c}E s t-6^{1} O d h^{2} \\
0.62624 \\
(0.61176)\end{array}$ & $\begin{array}{c}E s t-6^{2} O d h^{1} \\
0.05368 \\
(0.03919)\end{array}$ & $\begin{array}{c}E s t-6^{2} O d h^{2} \\
0.24056 \\
(0 \cdot 25504)\end{array}$ & +0.09 \\
\hline Low density & $\begin{array}{c}0.07415 \\
(0.08445)\end{array}$ & $\begin{array}{c}0.63771 \\
(0.62741)\end{array}$ & $\begin{array}{c}0.04449 \\
(0.03418)\end{array}$ & $\begin{array}{c}0.24364 \\
(0.25396)\end{array}$ & +0.07 \\
\hline $\begin{array}{l}E s t-6 \times O d h \times p i n k \\
\quad E s t+6^{1}\end{array}$ & $\begin{array}{c}O d h^{1} p \\
0.06946 \\
(0.01681)\end{array}$ & $\begin{array}{c}O d h^{1}+ \\
0.03907 \\
(0.09173)\end{array}$ & $\begin{array}{c}O d h^{2} p \\
0 \cdot 08538 \\
(0 \cdot 13804)\end{array}$ & $\begin{array}{c}O d h^{2}+ \\
0 \cdot 80607 \\
(0 \cdot 75342)\end{array}$ & $-0 \cdot 47$ \\
\hline Est- $6^{2}$ & $\begin{array}{c}0 \cdot 14436 \\
(0 \cdot 04463)\end{array}$ & $\begin{array}{c}0.02464 \\
(0 \cdot 12438)\end{array}$ & $\begin{array}{c}0 \cdot 11971 \\
(0 \cdot 21945)\end{array}$ & $\begin{array}{c}0.71126 \\
(0.61154)\end{array}$ & -0.60 \\
\hline
\end{tabular}

trigenic interaction $O d h \times$ pink $\times E s t-6$ is such that the correlation between alleles at the $O d h$ and pink loci is greater when the gametes carry an Est- $6^{2}$ allele $(+0.60)$ than it is when the Est- $6^{1}$ allele $(+0.47)$ is present.

The gametes produced by the adults in the cage population will show the effects of intrachromosomal recombination in the Drosophila female. Knowing: the map locations of the three loci it is possible to calculate expected frequencies of the four types of gamete, produced by adults in the cage population, from the observed gametic frequencies in the high density sample, by using the following relationship:

$$
\begin{array}{lc}
g_{1}^{\prime}=g_{1}+\frac{1}{2} R D & \\
g_{2}^{\prime}=g_{2}-\frac{1}{2} R D & \text { modified from } \\
g_{3}^{\prime}=g_{3}-\frac{1}{2} R D & \text { (Lewontin and Kojima, 1960) } \\
g_{4}^{\prime}=g_{4}+\frac{1}{2} R D &
\end{array}
$$

where the frequencies of the four types of gamete $(A B, A b, a B$ and $a b)$ are, at low density, $g_{1}^{\prime}, g_{2}^{\prime}, g_{3}^{\prime}$ and $g_{4}^{\prime}$ and at a high density $g_{1}, g_{2}, g_{3}$ and $g_{4}$. 
$R$ is the proportion of crossovers and $D$ the coefficient of linkage disequilibrium. The value of $R$ is divided by $\frac{1}{2}$ because there is no intrachromosomal recombination in the male $D$. melanogaster. The proportion of crossovers was calculated for each two locus pair from the map distances given in Lindsley and Grell (1967). The expected frequencies may be compared with the observed frequencies of the four types of gamete in the low density sample by a $\chi^{2}$ test for three degrees of freedom. The three degrees of freedom were partitioned into two comparisons each with one degree of freedom comparing the observed and expected allele frequencies of the two loci, and the remaining orthogonal comparison, which tests the observed linkage disequilibrium at low density with that expected to be produced by the cage population before selection. As recombination does not alter the allele frequencies only the $\chi_{(1)}^{2}$ for the comparison of linkage disequilibrium is shown below for each locus pair

$\begin{array}{lll}\text { Locus pair } & \chi_{(1)}^{2} & \mathrm{P} \\ \text { Odh-pink } & 3.02 & 10 \% \\ \text { Est-6-pink } & 0.66 & 40 \% \\ \text { Odh-Est-6 } & 0.03 & 85 \%\end{array}$

The $\chi^{2}$ tests show that the linkage disequilibrium in the low density sample does not differ from that expected to be produced by recombination from the sample of high density flies. Selection is not effective at low density.

Polymorphism at the pink locus was first observed in September 1968. The frequency of the pink homozygote has been monitored for 3 years. The samples (table 4) are large, and do show a fluctuation in the frequency

TABLE 4

Frequency of the pink homozygote in the "Texas" population

$\begin{array}{cccc} & \overbrace{p} & + & \text { \% pink homozygote } \\ \text { Sample date } & \text { Phenotypes } & & \\ 26.1 .71 & 33 & 1217 & 2 \cdot 64 \\ 10.12 .71 & 69 & 1428 & 4 \cdot 61 \\ 17.9 .73 & 137 & 5037 & 2 \cdot 65\end{array}$

of the pink homozygote $\left(\chi_{(2)}^{2}=15.99, \mathrm{P} \bumpeq 0.1\right.$ per cent $)$, but, there has been no tendency for the frequency of the pink homozygote consistently to increase or decrease in the population.

Some idea of the stability of the linkage disequilibrium between the $O d h$ and pink loci is known for a sample of 94 chromosomes from flies grown at low density 9 months prior to the main experiment reported in this paper.

The frequencies of the four types of gamete $O d h^{1} p, O d h^{1}+, O d h^{2} p$ and $O d h^{2}+$, were compared with those of the low density sample, and gave a $\chi_{(3)}^{2}$ of $1 \cdot 79, \mathrm{P} \bumpeq 20$ per cent. There is no evidence to suggest that the linkage disequilibrium between these two loci is transient.

\section{Discussion}

In this study the maximum separation between any two of the three loci was about 12.4 centimorgans $(O d h$ and $E s t-6)$. The two most tightly linked loci (Odh and pink), showed the strongest linkage disequilibrium and the two 
most loosely linked loci (Odh and Est-6) the least linkage disequilibrium. The strong trigenic interaction means that none of the linkage disequilibria observed at the digenic level is independent; a highly correlated genecomplex constitutes part of the genetic architecture of this chromosome segment. Although only the disequilibrium between the Odh and pink loci was affected by density, the linkage disequilibria observed at low density between these two loci did not differ from those which would be expected to be produced by a sample of flies raised at high density. In addition, the correlation between alleles at any two of the three loci, was always greatest at high density. These observations are in agreement with the hypothesis that the disequilibria are maintained by natural selection. Further analyses of the behaviour of these polymorphisms are being made with the "Texas" population.

Acknowledgment.-Dr M. J. Kearsey and Dr B. W. Barnes are thanked for helpful discussion.

\section{RefERENCES}

Allard, R. W., BABbel, G. R., ClegG, M. T., AND KAHLER, A. L. 1972. Evidence for coadaptation in Avena barbata. Proc. Nat. Acad. Sci., U.S.A., 69, 3043-3048.

AyAla, F. J., AND POWEll, J. R. 1972. Enzyme variability in the Drosophila willistoni group. VI. Levels of polymorphism and the physiological function of enzymes. Biochem. Genet., $7,331-345$.

Ayala, F. J., POWEll, J. R., Tracey, M. L., MOURÃo, C. A., AND PEREZ-SAlas, s. 1972. Enzyme variability in the Drosophila willistoni group. IV. Genic variation in natural populations of Drosophila willistoni. Genetics, 70, 113-139.

BARNES, B. W., AND KEARSEY, M. J. 1970. Variation for metrical characters in Drosophila populations. I. Genetic analysis. Heredity, 25, 1-10.

CHARLESWORTH, B., AND CHARLESWORTH, D. 1973. A study of linkage disequilibrium in populations of Drosophila melanogaster. Genetics, 73, 351-359.

CLEGG, M. T., AllARD, R. W., AND KAHLER, A. L. 1972. Is the gene the unit of selection? Evidence from two experimental plant populations. Proc. Nat. Acad. Sci., U.S.A., 69, 2474-2478.

FRANKLIN, I., AND LEWONTIN, R. c. 1970. Is the gene the unit of selection? Genetics, 65, 707-734.

HARRIS, H. 1966. Enzyme polymorphisms in man. Proc. Roy. Soc. B., 164, 298-310.

HARRIS, H. 1969. Enzyme and protein polymorphisms in human populations. British Medical Bulletin, 25, 5-13.

HUBBY, J. L., AND LEWONTIN, R. C. 1966. A molecular approach to the study of genic heterozygosity in natural populations. I. The number of alleles at different loci in Drosophila pseudoobscura. Genetics, 54, 577-594.

kendall, M. G., and stuart, A. 1961. The Advanced Theory of Statistics. Vol. 2. Inference and Relationship. Charles Griffin and Company Limited, London.

LEwontin, R. C., AND HUBBY, J. L. 1966. A molecular approach to the study of genic heterozygosity in natural populations. II. Amounts of variation and degree of heterozygosity in natural populations of Drosophila pseudoobscura. Genetics, 54, 595-609.

LEWONTIN, R. C., AND KOJIMA, K. 1960. The evolutionary dynamics of complex polymorphisms. Evolution, 14, 458-472.

LINDSLEY, D. L., AND GRELL, E. H. 1967. Genetic variations of Drosophila melanogaster. Carnegie Institution of Washington, Publication No. 627, Washington, D.C.

MUKAI, T., METTLER, L. E., AND ChIGUSA, s. I. 1971. Linkage disequilibrium in a local population of Drosophila melanogaster. Proc. Nat. Acad. Sci., U.S.A., 68, 1065-1069.

poulik, M. D. 1957. Starch gel electrophoresis in a discontinuous system of buffers. Nature, $180,1477-1479$.

SELANDER, R. K., AND YANG, s. Y. 1969. Protein and genic heterozygosity in a wild population of the house mouse (Mus musculus). Genetics, 63, 653-667. 